\title{
Por un populismo de
}

\section{¿ izquierda, de Chantal Mouffe}

\section{Introducción: el problemático concepto de populismo}

El populismo se ha convertido en una palabra ubicua del lenguaje político contemporáneo pero su existencia no es nueva. El concepto ya se usaba para denominar a movimientos decimonónicos en Rusia y Estados Unidos; o a los gobiernos de Perón, Lázaro Cárdenas, Velasco Alvarado o Getulio Vargas en América Latina; por no hablar de las lejanas raíces latinas del vocablo y su correlato en la política romana.

En los últimos años, la producción intelectual sobre el tema se ha incorporado con fuerza a la agenda de la academia y el mundo editorial desde los más variados ángulos. Se han multiplicado las obras que abordan el populismo: desde las que ofrecen una especie de "estado del arte" (Casullo, 2019; Rivero et al, 2018; De la Torre, 2018; Mudde \& Rovira Kaltwasser et al, 2017; Mudde \& Rovira Kaltwasser, 2013), las que lo estudian como resultado de otros fenómenos como las crisis financieras o el resquebrajamiento del patronazgo de los partidos tradicionales (Kenny, 2017; Tooze, 2018); pasando por números monográficos de revistas políticas (Nueva Sociedad, 2017) y columnas de opinión y paneles de análisis en influyentes medios de comunicación y tanques de pensamiento del establishment occidental (Foreign Affairs, Nov/Dic 2016; Institut Français des Relations Internationales, 15/04/2017; Chatham House, 24/10/2018; Carnegie Europe, 10/01/2019; Washington Post, 22/01/2019; Le Monde, 12/02/2019; Bloomberg, 22/03/2019; New York Times, 8/5/2019). En la mayoría de casos, el populismo es tratado como un fenómeno indeseable, y suele asociarse al autoritarismo o a la demagogia; o se le utiliza como etiqueta útil para deslegitimar a los enemigos políticos.

La filósofa y politóloga belga Chantal Mouffe se inscribe en esa discusión retomando una perspec- 
tiva teórica fuertemente asentada en Hegemonía y estrategia socialista. Hacia una radicalización de la democracia (Laclau y Mouffe, 1987) y La razón populista (Laclau, 2005). Estos textos causaron revuelo en tanto suponían una fuerte crítica contra la perspectiva marxista tradicional -a la que tacharon de "esencialista"por abordar la clase social como una categoría estática y cerrada. Pusieron a dialogar a Maquiavelo y Schmitt en paralelo con una lectura heterodoxa de Gramsci; mientras oponían el antagonismo de lo político frente al consenso neoliberal. En La razón populista, Laclau define el populismo como una estrategia discursiva en la que se establece una frontera política que opone a la sociedad en dos campos antagónicos y convoca a "los de abajo" contra quienes están en el poder. La honda brecha entre las instituciones y los diversos reclamos que no son procesados satisfactoriamente se convierten en demandas que al volverse equivalentes permiten la articulación colectiva del "pueblo".

\title{
2. El momento populista como oportunidad para radicalizar la democracia
}

En Por un populismo de izquierda, libro al que Mouffe confiere una naturaleza "partisana", se retoma esta tradición de análisis para reflexionar sobre el "momento populista" que está sustituyendo a una resque- brajada "hegemonía neoliberal". La autora reivindica que sea la izquierda y no los populistas de derecha quien aproveche el espacio. El argumento central de la obra es que

\begin{abstract}
para poder intervenir en la crisis hegemónica, es imprescindible establecer una frontera política, y que el populismo de izquierda -entendido como estrategia discursiva de construcción de la frontera política entre "el pueblo" y "la oligarquía"- es el tipo de política requerido [sic] para recuperar y profundizar la democracia (Mouffe, 2018: 17).
\end{abstract}

La autora desarrolla su argumento en cuatro partes: el momento populista, el thatcherismo, la radicalización de la democracia y la construcción de un pueblo. De esta forma describe un proceso de ruptura hegemónica, con la propuesta de llevar la democracia más allá de sus fronteras liberales y construir discursivamente al pueblo como un sujeto heterogéneo que se define políticamente frente a un "otro" de carácter "agonístico", es decir, no como en la relación "amigo-enemigo" a lo Schmitt, sino como "adversario" en un escenario de pluralismo y reconocimiento mutuo. 
Mientras Kenny (2017) revisa distintas concepciones de populismo (como ideología, como movilización y como tipo de partido); Mouffe aclara que no se trata de una ideología, ni de un programa, ni de un régimen político. Es "un modo de hacer política que puede adoptar diversas formas ideológicas en función del momento y del lugar, y que es compatible con variedad de marcos institucionales" (2018: 25). De acuerdo a la autora, el "momento populista" ocurre cuando ante determinadas transformaciones "la multiplicación de demandas insatisfechas desestabiliza la hegemonía dominante". En sintonía con Laclau, Mouffe observa que la gente deja de ser leal a las instituciones y el orden vigente a la vez que el bloque histórico en que basaba la sociedad se desarticula "y surge la posibilidad de construcción de un nuevo sujeto de la acción colectiva -el pueblo- capaz de reconfigurar un orden social experimentado como injusto".

Una situación semejante ocurrió en los años ochenta del siglo pasado cuando emergió una crisis hegemónica del consenso de posguerra entre tories y laboristas. De acuerdo a Mouffe, la llegada de Margaret Thatcher al gobierno británico significó una ruptura en la que se puede identificar una estrategia claramente populista. La primera ministra trazó una frontera entre un establishment compuesto por burócratas, sindicatos y beneficiarios de ayudas sociales, por un lado; y la gente "industriosa" lastrada por esas fuerzas opresoras de la libertad. Frente al tipo de intervención pública que caracterizaba al Estado de Bienestar de la posguerra se imponía un nuevo "sentido común" neoliberal ${ }^{1}$.

Tras décadas de esa hegemonía neoliberal a la que se sumaron también los laboristas y eventualmente todos los socialdemócratas europeos, se presenta nuevamente un "momento populista".Actualmente se posibilita la construcción de una nueva formación hegemónica, que podrá ser más autoritaria o más democrática, según sea la derecha o la izquierda la que mejor provecho saque de esta ventana de oportunidad. Una formación hegemónica es

una configuración de prácticas sociales de diferente naturaleza-económica, cultural, política, jurídica- cuya articulación se sostiene con ciertos significantes simbólicos clave que constituyen el 'sentido común'y proporcionan el marco normativo de una sociedad dada. El objetivo de la lucha hegemónica consiste en desarticular las prácticas sedimentadas de una formación existente y mediante la transformación de estas prácticas y la instauración de otras nuevas, establecer los puntos nodales. de una nueva formación social hegemónica. Mouffe (2018: p. 66) 
Para la autora es importante subrayar que una ruptura del orden neoliberal pasa por recuperar y radicalizar la democracia, abandonando el falso dilema que planteaba que romper con la formación hegemónica implicaba abandonar los postulados de la democracia liberal. Todo lo contrario. El problema del neoliberalismo es reducir la representación a las elecciones y más bien lo que se requiere es llevarla más allá, algo que no es incompatible con la dimensión anticapitalista de la democracia radical. No se trata de abolir la representación sino que las instituciones sean más representativas. Frente al pluralismo armónico observable en el giro "pospolítico" de la era neoliberal, Mouffe sostiene que el pluralismo sólo puede ser efectivo bajo el supuesto de "una confrontación agonística de proyectos hegemónicos (p. 79). En Mouffe no hay "fin de la historia" posible, sino una permanente reconstitución de las fronteras de lucha.

\section{La construcción de un pueblo}

En la la estrategia populista de izquierda la "cuestión social "se vuelve central y toma en cuenta la fragmentación y diversidad de "los trabajadores" y la especificidad de las demandas democráticas. Ya no se puede hablar del proletariado como la esencia de la izquierda y portador de los intereses comunes de todas las clases dominadas; en el populismo se requiere construir al pueblo "en torno a un proyecto que aborde las diversas formas de subordinación en relación con cuestiones de explotación, dominación o discriminación" (p. 85). Esto incluye las demandas de las mujeres y el futuro del planeta, asuntos postergados por los marxistas tradicionales ${ }^{2}$. Mouffe reitera lo ya dicho por Laclau en el sentido de que la construcción de pueblo no se constituye bajo una unidad resultante de la homogeneidad, sino de una cadena de equi- valencias que derivan en voluntad colectiva. En esta relación equivalencial, las diferencias no sucumben en la identidad, sino que se mantienen activas.

La autora subraya además que el pueblo "no constituye un referente empírico, sino una construcción política discursiva [...] no tiene una existencia previa a su articulación performativa y no puede ser aprehendido mediante categorías sociológicas" (p. 86). En este sentido es necesario destacar que el adversario tampoco preexiste, porque el pueblo dibuja las demarcaciones que lo separan de sus adversarios de forma concomitante a la lucha por la hegemonía, a través del discurso y la rearticulación. Para Mouffe "las demandas democráticas que la estrategia populista de izquierda pretende articular son heterogéneas, 
y por esta razón deben articularse en una cadena de equivalencia" ( $p$. 88). En ese nivel se encuentra la lucha obrera, ecologista, feminista o campesina, y de ninguna manera se puede insistir en ese concepto de vanguardia, inadecuado ante la misma complejización de los procesos sociales.

A modo de cierre, es necesario decir que el texto de Mouffe permite problematizar el debate actual sobre el populismo, que lo concibe como un peligro para la democracia, e introduce un ángulo que considera, en constraste, que un populismo de izquierda es capaz de radicalizar la democracia a partir de una nueva formación hegemónica que supere tanto al consenso neoliberal como los enfoques esencialistas. Es un retorno de lo político para superar la pospolítica.

\section{Referencias bibliográficas}

- Cadier, David. “How Populism Spills Over Into Foreign Policy”. En Carnegie Europe, edición del 10 de enero de 2019. Disponible en https://carnegieeurope.eu/strategiceurope/78102. Recuperado el 14 de mayo de 2019.

- Casullo, M. (2019) ¿Por qué funciona el populismo? El discurso que sabe construir explicaciones convincentes de un mundo en crisis. Buenos Aires: Siglo XXI Editores.

- Chatham House. The Royal Institute of International Affairs. "Chatham House Primer: National Populism". Chatham House, 24 de octubre 2018. En https://www.chathamhouse.org/event/chatham-house-primer-nationalpopulism. Recuperado el 14 de mayo de 2019.

- De la Torre, C. (Ed.). (2018). Routledge Handbook of Global Populism. Routledge.

- Gideon, Rose. "The power of populism. What's inside". Foreign Affairs, noviembre/diciembre 2016. En https://www.foreignaffairs.com/articles/2016-10-17/power-populism. Recuperado el 14 de mayo de 2019.

- Gramsci A. (1984). Cuadernos de la Cárcel. Tomo 3. México, D.F. Ediciones Era.

- Laclau, E. (2005). La razón populista. Buenos Aires: Fondo de Cultura Económica.

- Laclau, E., \& Mouffe, C. (1987). Hegemonía y estrategia socialista: hacia una radicalización de la democracia. Madrid: Siglo XXI.

- LaTuerka. "Otra Vuelta de Tuerka - Pablo Iglesias con Chantal Mouffe (Programa completo)". Programa 18, emisión del domingo 15 de febrero de 2015. Disponible en https://www.youtube.com/watch?v=BXS5zqijfA4 
- Mouffe, C. (2018). Por un populismo de izquierda. Buenos Aires: Siglo Veintiuno editores.

- Mudde, C., \& Rovira Kaltwasser, C. (2018). "Studying populism in comparative perspective: Reflections on the contemporary and future research agenda". Comparative Political Studies, 51(13), 1667-1693.

- VV AA. "El Fantasma del populismo". Nueva Sociedad 267, enero-febrero 2017.

- Mudde, C., \& Kaltwasser, C. R. (2017). Populism: A very short introduction. Oxford University Press.

- Müller, Jan-Werner. “Populists Don't Lose Elections”. New York Times. Opinion, 8 de mayo de 2019. En https://www.nytimes.com/2019/05/08/ opinion/populists-dont-lose-elections.html Consultado el 14 de mayo de 2019.

- O'Brian, Fergal. "Populists and Authoritarians Have Taken Over the World Economy”. Bloomberg, edición del 22 de marzo de 2019. Disponible en https://www.bloomberg.com/news/articles/2019-03-22/populists-arerunning-70-percent-of-world-s-biggest-economies. Recuperado el 14 de mayo de 2019.

- Soullier, Lucie; y Mestre, Abel. "Le populisme, nouvelle grammaire politique". Le Monde, edición del 12 de febrero de 2019. Disponible en https:// www.lemonde.fr/politique/article/2019/02/12/le-populisme-nouvellegrammaire-des-leaders-politiques_5422257_823448.html. Recuperado el 14 de mayo de 2019.

- Tooze,J. A. (2018). Crash: Cómo una década de crisis financieras ha cambiado el mundo. Barcelona. Crítica.

\section{Notas}

1 De acuerdo a Gramsci (1975: 303) la filosofía del sentido común es la "filosofía de los no filósofos", es decir "la concepción del mundo absorbida acríticamente por los diversos ambientes sociales en los que se desarrolla la individualidad moral del hombre medio".

2 Este debate estaba presente ya desde la aparición de Hegemonía y estrategia socialista. Mouffe ofrece una descripción más detallada en el programa "La Otra Tuerka", donde conversa con el ex catedrático de ciencia política y Secretario General de Podemos, Pablo Iglesias. (Programa 18, Emisión del domingo 15 de febrero de 2015.) 